\title{
ROS Scavenging and Nitrate Reductase Enzyme Activity in Mungbean [Vigna radiata (L.) Wilczek] under Drought Stress
}

\author{
Sibu Mandi ${ }^{1}$, Anjan Kumar Pal ${ }^{1}$, Rajib Nath $^{2}$ and Suryakant Hembram ${ }^{\text {* }}$ \\ ${ }^{1}$ Department of Plant Physiology, Faculty of Agriculture, Bidhan Chandra Krishi \\ Viswavidyalaya, Mohanpur, Nadia, West Bengal, India \\ ${ }^{2}$ Department of Agronomy, Faculty of Agriculture, Bidhan Chandra Krishi Viswavidyalaya, \\ Mohanpur, Nadia, West Bengal, India \\ *Corresponding author
}

\section{A B S T R A C T}

Water deficit and salt stresses are global issues related to survival of agricultural crops and sustainable food production. Drought stress occurs when the available water in soil is

\section{Keywords}

Mungbean, Drought Stress, Guaiacol

peroxidase, Superoxide dismutase, Catalase and

Nitrate reductase

Article Info

Accepted:

10 March 2018

Available Online:

10 April 2018 reduced and atmospheric condition cause continuous loss of water by transpiration and evaporation. The general complexity of drought is often aggravated under conditions of erratic and unpredictable rainfall and by the occurrence of high temperature, high levels of solar radiation and poor soil characteristics. A key to progress towards breeding for better crop varieties under drought stress is to understand the biochemical, physiological and molecular machinery that are induced under such stress. The present experiment was envisaged to i) study the effect of drought stress on seedling growth of few genotypes of mungbean and to rank them on the basis of their tolerance and ii) study the physiological and biochemical changes in selected tolerant and susceptible genotypes to have an understanding of physiological basis of drought tolerance. The drought stress was imposed using a solution of polyethylene glycol (PEG) 6000 creating an osmotic potential of -1.5 $\mathrm{MPa}$. A control set containing distilled water was also prepared for comparison. The higher activities of ROS scavenging enzymes, SOD, GPOX and catalase helped the tolerant genotypes to combat against drought-induced oxidative stress in much better way than the susceptible ones.

\section{Introduction}

Plants are frequently exposed to different types of stress, viz., drought, low temperature, salinity, flooding, heat, heavy metal toxicity etc. Generally drought stress occurs when the available water in soil is reduced and atmospheric condition cause continuous loss of water by transpiration and evaporation. Water deficit and salt stresses are global issues to ensure survival of agricultural crops and sustainable food production (Jaleel et al., 2009). Of the total cultivated area of 1600 million hectares in the world, about 1300 million hectares (80 percent) are rainfed (FAO, 2011). Although rainfed agriculture produces about 60 percent of global crop output in a wide variety of production systems, but the areas under this system is very much prone to drought stress due to 
erratic and skewed distribution of rainfall. On an average, around $28 \%$ of the geographical area of India is vulnerable to drought (Samra, 2004). Drought results in reduction of water content, diminished leaf water potential and turgor loss, closure of stomata and limitation of gas exchange. Severe water stress may result in arrest of photosynthesis, gross disruption of metabolism and cell structure and eventually the cessation of enzyme catalyzed reaction and death of plant (Smirnoff, 1993; Jaleel et al., 2008c).

Plant responses to drought stress are very complex as stress itself involves various climatic, edaphic and agronomic factors, frequently complicated by major variation in timing of occurrence, duration and intensity as well as stage of crop growth. The general complexity of drought is often aggravated under conditions of erratic and unpredictable rainfall and by the occurrence of high temperature, high levels of solar radiation and poor soil characteristics. Moreover, all the stages of plant growth are not equally sensitive to drought stress. The germination and early seedling stage and the grain filling stage are often considered as most critical stages that are sensitive to drought stress. A key to progress towards breeding for better crop varieties under drought stress is to understand the biochemical, physiological and molecular machinery that are induced under such stress. Thus, it is essential to study the physiological and biochemical changes that are triggered in a plant when it is subjected to drought stress.

Mungbean [Vigna radiata (L.) Wilczek] is an important leguminous species and is among the most important pulse crops in subtropical zones of the word. It is considered as one of the cheap sources of dietary proteins in our country. The seeds contain $22-28 \%$ protein, 60-65 \% carbohydrates, $1-1.5 \%$ fat, 3.5-4.5\% fibres and $4.5-5.5 \%$ ash (Mohamed and
Kramany, 2005). Mungbean is also characterized by its ability to improve the physical, chemical and biological properties of soil. It can also increase the soil fertility through biological nitrogen fixation from atmosphere.

The growth and productivity of mungbean in arid and semi-arid regions is often affected adversely by drought stress. Different developmental stages of this crop are sensitive to moisture stress. So far some research works have already been carried out on the effect of drought stress on morpho-physiological and biochemical characteristics of mungbean (Kumar and Singh, 1991; Naidu et al., 2001 Dutta and Bera, 2007 Allahmoradi et al., 2011 Uddin et al., 2013; Ranawake et al., 2011; Aslam et al., 2013). But there is dearth of information regarding the physiology of drought tolerance at early seedling stage in this crop.

\section{Materials and Methods}

Seeds of 18 genotypes (Pusa 9531, Pusa 031, Pusa Vishal, SML 1205, IPM 9901-6, Meha, Pusa 032, Pant Mung 2, SML 1194, NDM 11 15, IPM 2K 14-9, Pant Mung 5, Pusa 1131, Pusa 1132, NVL 638, IPM 9901-10, CZMK-1 and Pusa 1172) of mungbean [Vigna radiata (L.) Wilczek] were screened and among them four tolerant (Pusa 1131, Meha, Pusa 9531 and NVL 638) and four susceptible (Pusa 1132, IPM 9901-10, IPM 9901-6 and Pusa 1172) genotypes were identified and used in the experiment. The seeds were collected from Dr. Rajib Nath, Professor, Department of Agronomy Bidhan Chandra Krishi Viswavidyalaya, Mohanpur, Nadia. For screening of genotypes for drought tolerance at germination and early seedling growth stage, moisture stress was imposed in the laboratory using solution of polyethylene glycol 6000 (PEG 6000). The empirical formula for calculating osmotic potential $\left(\psi_{\mathrm{s}}\right)$ 
given by Michel and Kaufmann (1973) as follows:

$\psi_{\mathrm{s}}=-\left(1.18 \times 10^{-2}\right) \mathrm{C}-\left(1.18 \times 10^{-4}\right) \mathrm{C}^{2}+$ $\left(2.67 \times 10^{-4}\right) \mathrm{CT}+\left(8.39 \times 10^{-7}\right) \mathrm{C}^{2} \mathrm{~T}$

Where,

$\psi_{\mathrm{s}}=$ Osmotic potential (in bars)

$\mathrm{C}=$ Concentration of PEG $6000\left(\mathrm{~g} \mathrm{~kg}^{-1} \mathrm{H}_{2} \mathrm{O}\right)$

$\mathrm{T}=$ Temperature $\left({ }^{\circ} \mathrm{C}\right)$

Using the table of Michel and Kaufmann (1973) a solution was prepared by dissolving appropriate amount of PEG 6000 in distilled water to create an osmotic potential of -1.5 $\mathrm{MPa}$.

Seeds of 18 genotypes of mungbean were surface sterilized with $0.1 \% \mathrm{HgCl}_{2}$ (w/v) for 2 minutes followed by thorough washing in distilled water. Twelve seeds were arranged in a row over a glass plate $(20 \times 30 \mathrm{~cm})$ lined with blotting paper separately. The whole set was then placed in a transparent polythene bag containing $70 \mathrm{ml}$ of PEG solution. The seedlings were allowed to develop for 10 days under indoor laboratory conditions of bright diffused light, $70-80 \%$ relative humidity (R.H.) and at a temperature range of $28 \pm 1^{\circ} \mathrm{C}$. Surface sterilized seeds treated similarly with glass distilled water served as control. Three replicates were maintained in all cases including control.

Ten days old seedlings were removed from the glass plate for the following growth parameters. Guaiacol peroxidase activity was measured by a method of Siegel and Galston (1967). Determination of superoxide dismutase activity was performed as per the method of Giannopolitis and Ries (1977). Catalase activity was measured by an assay of hydrogen peroxide on the basis of its formation of a stable complex with ammonium molybdate (Goth, 1991).
Extraction of nitrate reductase and the estimation of enzyme activities were done as per Jaworski (1971).

\section{Results and Discussion}

Plants often undergo perturbation in the equilibrium between productions and scavenging of different reactive oxygen species (ROS) by various biotic and abiotic stress factors, such as salinity, drought, heavy metals, UV radiation, pathogen attacks etc. These disturbances in equilibrium lead to sudden increase in intracellular levels of ROS leading to oxidative stress which can cause significant damage to cell structure. To protect themselves against these toxic oxygen intermediates, plant cells contain both enzymatic and non-enzymatic components. Among the enzymatic antioxidants, superoxide dismutase (SOD), catalase (CAT), ascorbate peroxidase (APX), guaiacol peroxidase (GPOX) have been found to be very important. In the present experiment, the activities of superoxide dismutase (SOD), catalase (CAT) and guaiacol peroxidase (GPOX) were measured under drought stress and control condition to get an idea about enzymatic scavenging system in the eight genotypes under stress. Statistical analysis indicated highly significant differences for treatment, genotype and treatment $\mathrm{x}$ genotype interaction in all the cases except for superoxide dismutase (SOD) activity (Figure 1 and Table 1). In case of SOD activity the treatment $\mathrm{x}$ genotype interaction showed nonsignificant variation. The activity of SOD in the leaves of eight genotypes varied from 10.108 to 16.497 Unit $\min ^{-1} \mathrm{~g}^{-1}$ fresh weight under control condition, while that under PEG treatment varied from 12.643 to 21.991 Unit $\min ^{-1} \mathrm{~g}^{-1}$ fresh weight. All the genotypes registered increase in the activity of SOD under drought stress over control with tolerant genotypes showing higher increase than the susceptible ones. 
Table.1 Effect of drought stress on guaiacol peroxidase (GPOX) and catalase (CAT), superoxide dismutase (SOD) and nitrate reductase (NR) activity in the leaves of eight mungbean genotypes

\begin{tabular}{|c|c|c|c|c|c|c|c|c|}
\hline \multirow[t]{2}{*}{ Genotypes } & \multicolumn{2}{|l|}{ GPOX $^{a}$} & \multicolumn{2}{|l|}{ Catalase $^{\mathrm{b}}$} & \multicolumn{2}{|l|}{$\mathrm{SOD}^{\mathrm{c}}$} & \multicolumn{2}{|l|}{$\mathrm{NR}^{\mathrm{d}}$} \\
\hline & Control & Treatment & Control & Control & Control & Treatment & Control & Treatment \\
\hline Pusa 1131 & 3.627 & $\begin{array}{l}7.360 \\
(102.92)\end{array}$ & 134.226 & 160.000 & 160.000 & $\begin{array}{l}16.517 \\
(63.41)\end{array}$ & 3.304 & $\begin{array}{l}5.939 \\
(79.75)\end{array}$ \\
\hline Meha & 2.987 & $\begin{array}{l}7.733 \\
(158.89)\end{array}$ & 159.888 & 194.694 & 194.694 & $\begin{array}{l}21.991 \\
(33.30)\end{array}$ & 2.879 & $\begin{array}{l}4.915 \\
(70.72)\end{array}$ \\
\hline Pusa 9531 & 6.240 & $\begin{array}{l}9.227 \\
(47.87)\end{array}$ & 135.342 & 268.163 & 268.163 & $\begin{array}{l}18.047 \\
(48.60)\end{array}$ & 2.582 & $\begin{array}{l}4.412 \\
(70.88)\end{array}$ \\
\hline NVL 638 & 3.413 & $\begin{array}{l}6.133 \\
(79.70)\end{array}$ & 130.879 & 262.041 & 262.041 & $\begin{array}{l}14.858 \\
(24.89)\end{array}$ & 2.901 & $\begin{array}{l}6.515 \\
(124.58)\end{array}$ \\
\hline Pusa 1132 & 8.213 & $\begin{array}{l}8.373 \\
(1.95)\end{array}$ & 303.821 & 298.776 & 298.776 & $\begin{array}{l}21.522 \\
(21.65)\end{array}$ & 3.078 & $\begin{array}{l}5.159 \\
(67.61)\end{array}$ \\
\hline IPM 9901-10 & 8.107 & $\begin{array}{l}11.200 \\
(38.15)\end{array}$ & 161.004 & 243.673 & 243.673 & $\begin{array}{l}14.513 \\
(9.25)\end{array}$ & 2.882 & $\begin{array}{l}5.514 \\
(91.33)\end{array}$ \\
\hline IPM 9901-6 & 5.333 & $\begin{array}{l}3.360 \\
(-37.00)\end{array}$ & 212.329 & 241.633 & 241.633 & $\begin{array}{l}12.643 \\
(10.24)\end{array}$ & 2.421 & $\begin{array}{l}3.800 \\
(56.96)\end{array}$ \\
\hline Pusa 1172 & 10.133 & $\begin{array}{l}6.027 \\
(-40.52)\end{array}$ & 241.339 & 260.000 & 260.000 & $\begin{array}{l}15.352 \\
(14.46)\end{array}$ & 3.078 & $\begin{array}{l}4.270 \\
(38.73)\end{array}$ \\
\hline & S.E. $m( \pm)$ & C.D. $5 \%$ & S.E. $m( \pm)$ & C.D. $5 \%$ & S.E. $m( \pm)$ & C.D. $5 \%$ & S.E. $\mathrm{m}( \pm)$ & C.D. $5 \%$ \\
\hline Treatment (T) & 0.0817 & 0.2352 & 0.9739 & 2.8053 & 0.2818 & 0.8118 & 1.0594 & 3.0518 \\
\hline Genotypes (G) & 0.1633 & 0.4705 & 1.9477 & 5.6107 & 0.5636 & 1.6236 & 2.1188 & 6.1035 \\
\hline T x G & 0.2310 & 0.6654 & 2.7545 & 7.9347 & 0.7971 & NS & 2.9964 & 8.6317 \\
\hline
\end{tabular}

Data in parentheses indicate percent increase (+) or decrease (-) over control

${ }^{\mathrm{a}}$ Data expressed as $\Delta \mathrm{A} 470 \mathrm{~min}^{-1} \mathrm{~g}^{-1}$ fresh weight,

${ }^{\mathrm{b}}$ Data expressed as $\mu \mathrm{mol} \mathrm{H}_{2} \mathrm{O}_{2} \min ^{-1} \mathrm{~g}^{-1}$ fresh weight

${ }^{\mathrm{c}}$ Data expressed as Unit $\mathrm{min}^{-1} \mathrm{~g}^{-1}$ fresh weight

${ }^{\mathrm{d}}$ Data expressed as milli mol of $\mathrm{NO}_{2}$ formed $\mathrm{g}^{-1}$ fresh weight

NS=Non-significant

Fig.1 Percent increase or decrease in SOD activity of mungbean genotypes under drought stress

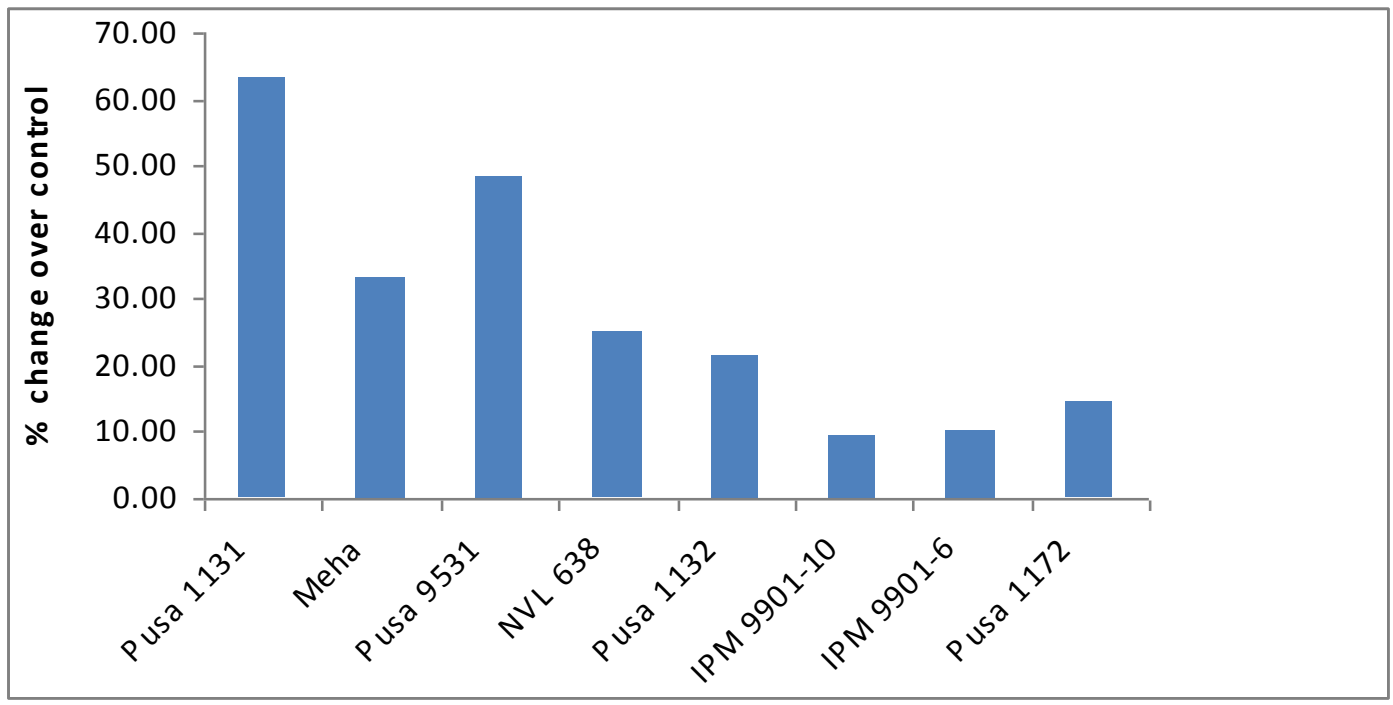


Fig.2 Percent increase or decrease in GPOX activity of mungbean genotypes under drought stress

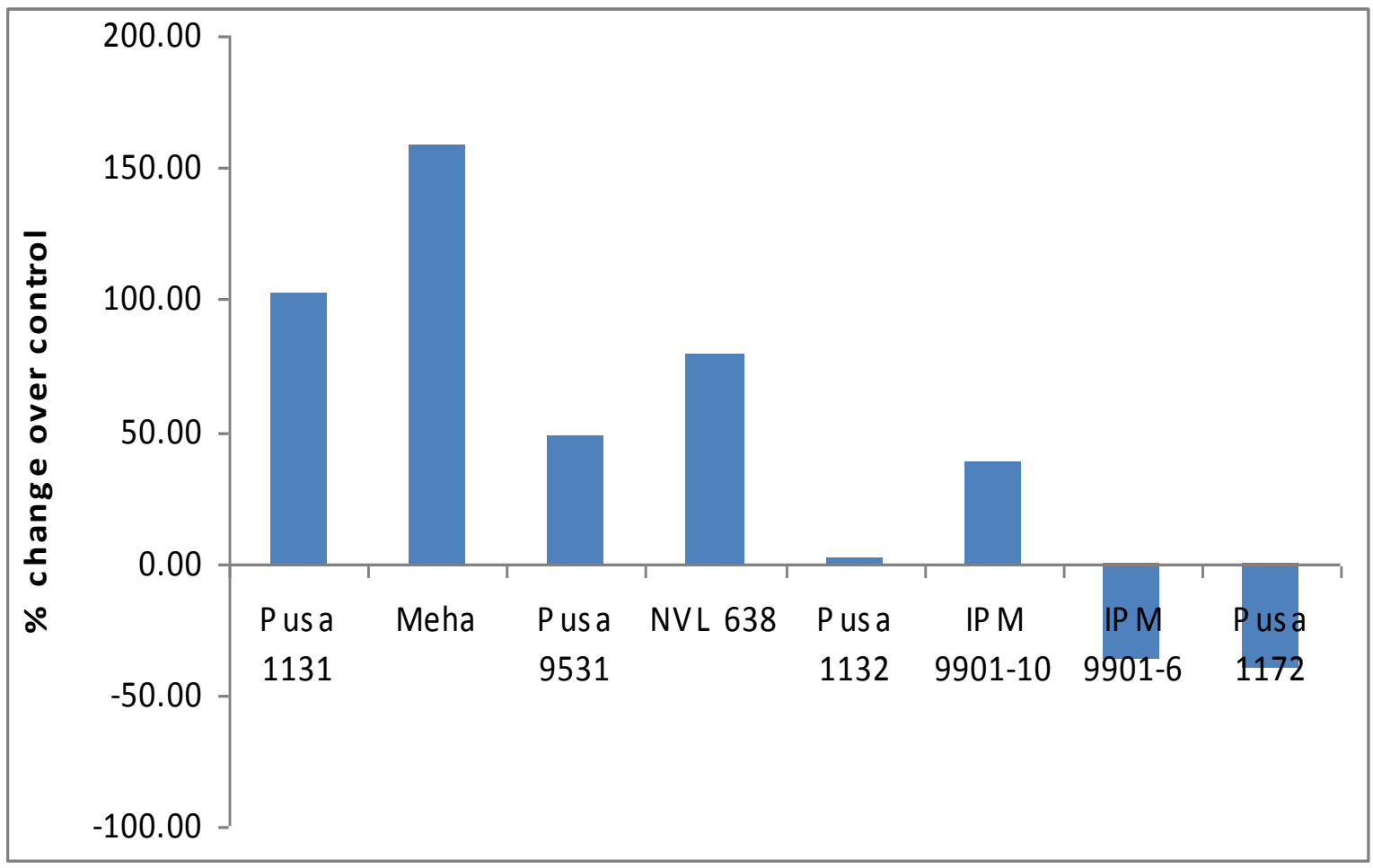

Fig.3 Percent increase or decrease in catalase activity of mungbean genotypes under drought stress

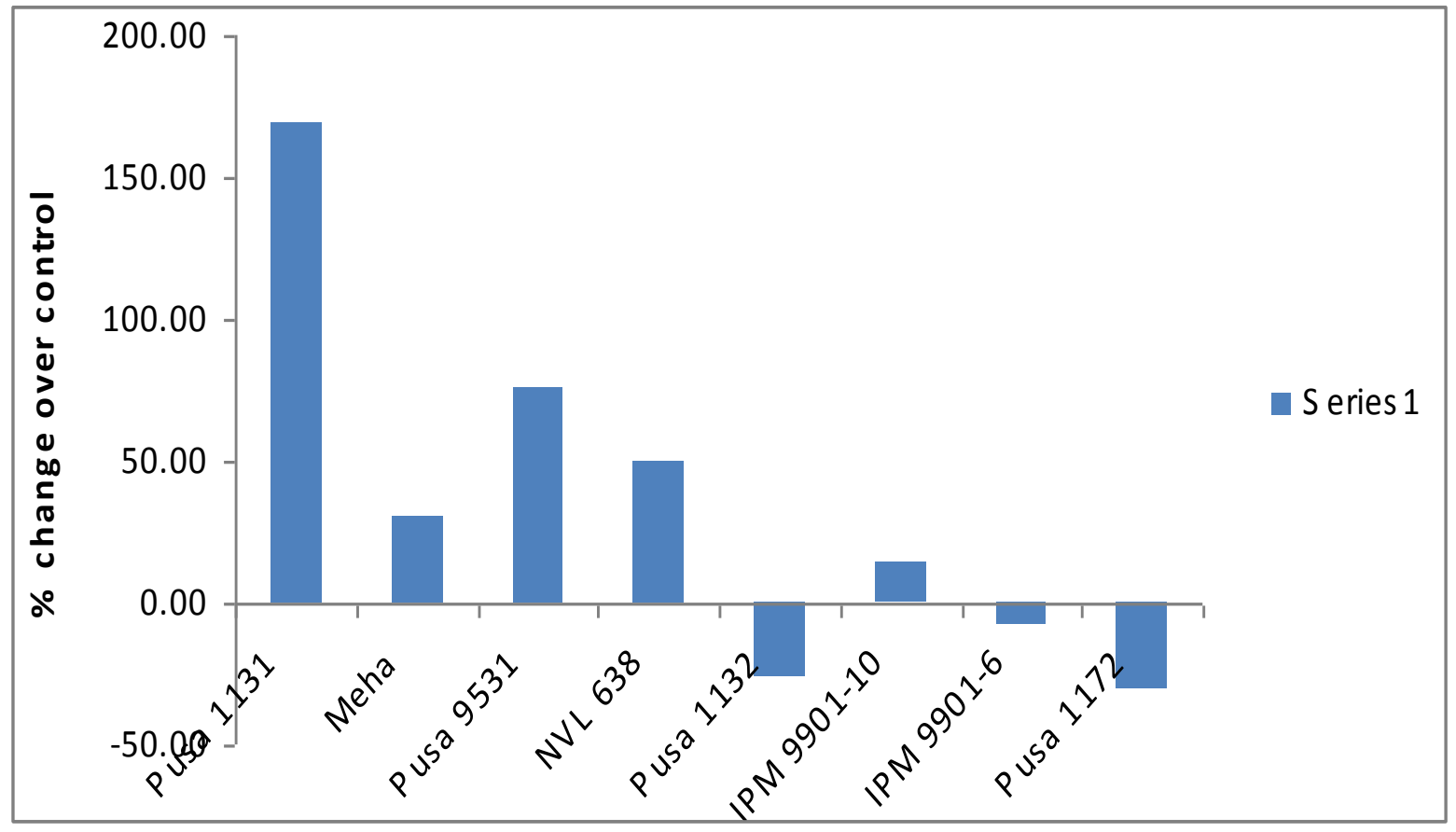


Fig.4 Percent increase or decrease in nitrate reductase activity of mungbean genotypes under drought stress

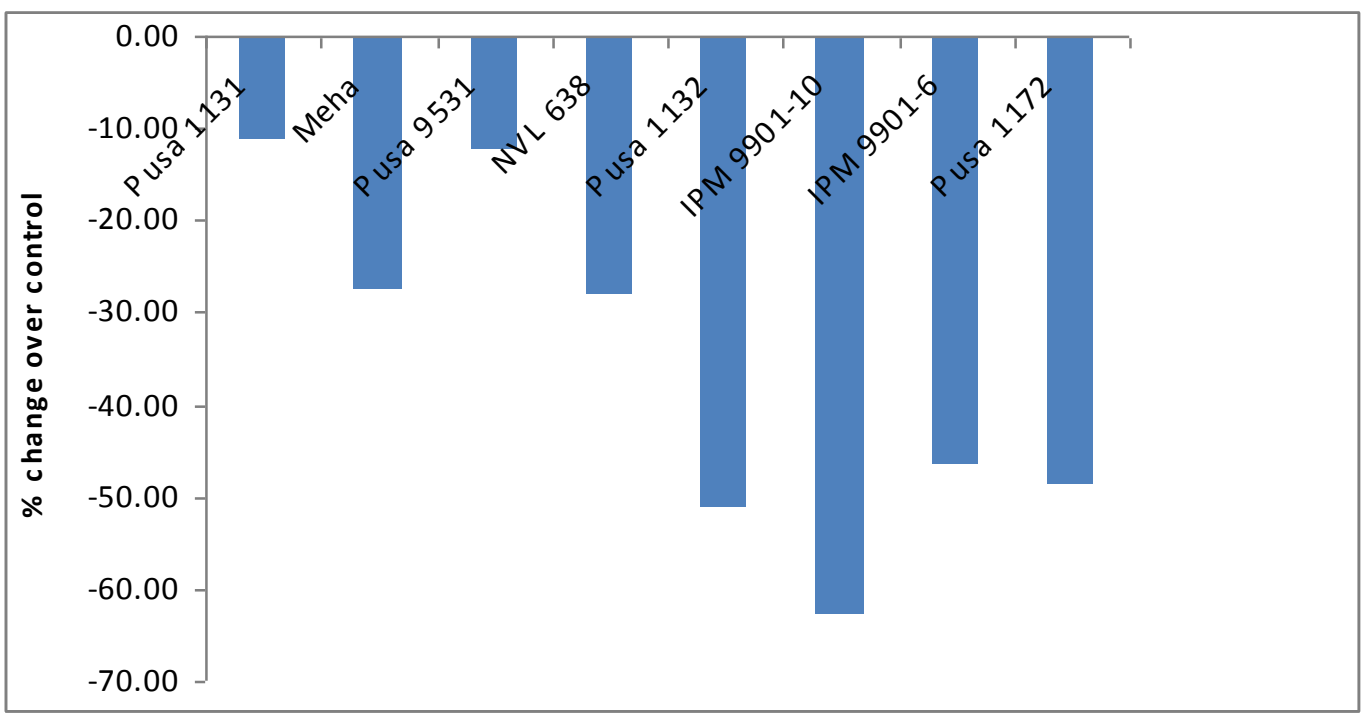

This might help the tolerant genotypes to scavenge the overproduction of superoxide radicals during oxidative stress in a better way than their sensitive counterparts. Increase in SOD activity following drought stress was also noted in different crops by Sairam et al., (2001), Zhang et al., (2003), Zlatev et al., (2006), Moussa and Abdel- Aziz (2008) and Abedi and Pakniyat (2010). However, in the present experiment, the tolerant genotype Pusa 1131 revealed the highest increase $(63.41 \%)$ in SOD activity under drought followed by Pusa 9531 (48.60\%). The susceptible genotypes, IPM 9901-10 and IPM 9901-6 had shown least level of SOD induction under drought and registered an increase of $9.25 \%$ and $10.24 \%$, respectively, over control.

The eight genotypes exhibited sharply contrasting behaviour in respect of activity of GPOX in the leaves under drought stress (Table 1 and Figure 2). The four tolerant genotypes registered 47.87 to $158.89 \%$ increase in GPOX activity under PEG treatment in comparison with the control condition. In contrast, the leaf GPOX activity decreased under drought stress in two out of four susceptible genotypes with Pusa 1172 being the most adversely affected. While the two other susceptible genotypes, Pusa 1132 and IPM 9901-10, registered only $1.95 \%$ and $38.15 \%$ increase in GPOX activity, respectively. Among the eight genotypes Meha indicated highest increase (158.89\%) in GPOX activity in the leaf followed by Pusa 1131 (102.92\%). A positive correlation between enhanced levels of peroxidases and drought tolerance was reported by Sairam et al., (1997), Zhang et al., (2003), Nair and Ramaswamy (2006), Moussa and Abdel- Aziz (2008) and Devi et al., (2011).

Like GPOX, the activity of catalase (CAT) enzyme in the leaves of the eight genotypes under study also revealed sharply contrasting behaviour under drought stress (Table 1 and Figure 3). The four tolerant genotypes exhibited substantial increase in CAT activity under drought stress and the range varied from $30.71 \%$ to $169.58 \%$ increase over control with Pusa 1131 registering the highest increase followed by Pusa 9531. The results were concordant with the early observations 
of Sairam and Srivastava (2001), Dalmia and Sawhney (2004), Moussa and Abdel-Aziz (2008) and Simova- Stoilova et al., (2010) who observed an increase in the activity of CAT under drought stress. In the present experiment, the catalase activity in the leaves of three of the susceptible genotypes decreased under drought stress with Pusa 1172 registering as much as $30.98 \%$ decrease. The remaining susceptible genotype, IPM 9901-10 showed an increase of $14.55 \%$ over control.

The treatments, genotypes as well as treatment $\mathrm{x}$ genotype interaction exhibited significant differences for nitrate reductase (NR) activity in leaf and leaf protein content (Table 1 and Figure 4). All the eight genotypes showed decrease in nitrate reductase activity in their leaves under PEG treatment. The decrease was more in the susceptible genotypes and the ranged varied from 46.45 to $62.81 \%$, whereas the corresponding values in the tolerant genotypes ranged from 11.10 to $28.04 \%$.

Nitrate reductase enzyme plays an important role in nitrogen metabolism of plants. The first step in the assimilation of nitrate in plants is the reduction of nitrate to nitrite by enzyme nitrate reductase in cytosol and is often considered to be the rate limiting step in nitrate metabolism. So, inhibition of the activity of this enzyme would have an adverse effect on the rate of nitrate assimilation.

The negative effects of drought on NR activity were reported in some early works by Satbhai et al., (1997), Deka (2000) and Das et al., (2005). In the present experiment, Pusa 1131 and Pusa 9531 were least affected for NR activity under drought stress and recorded a decrease of 11.10 and $12.18 \%$ decrease over control; while the NR activity in Meha was most drastically reduced $(62.81 \%)$ under drought stress.

\section{References}

Abedi, T. and Pakniyat, H. 2010. Antioxidant enzyme changes in response to drought stress in ten cultivars of oilseed rape (Brassica napus L.). Czech J. Genet. Plant Breed., 46: 27- 34.

Allahmoradi P., Ghobadi M., Taherabadi S. and Taherabadi S. 2011. Physiological Aspects of Mungbean (Vigna radiata L.) in Response to Drought Stress. International Conference on Food Engineering and Biotechnology. IPCBEE, vol. 9.

Aslam Md., Maqbool Md. A., Zaman Q., Latif Md. Z. and Ahmad R. M. 2013. Responses of Mungbean Genotypes to Drought Stress at early Growth Stages. International Journal of Basic \& Applied Sciences IJBAS-IJENS, Vol: 13 No: 05.

Dalmia, A. and Sawhney, V. 2004. Antioxidant defense mechanism under drought stress in wheat seedlings. Physiology and Molecular Biology of Plants, 10: 109 - 114.

Das, K., Pradhan, T., Ghosh, S. and Mishra, B. K. 2005. Evaluation of drought resistance characteristics of upland rice cultivars. Oryza, 42: $138-144$.

Deka, M. 2000. Effect of drought on physiological traits of upland ahu (rabi) rice (Oryza sativa L.) cultivars at vegetative stage. Crop Res., 19: 434439.

Devi, R., Kaur, N. and Gupta, A.K. 2011. Potential of antioxidant enzymes in depicting drought tolerance of wheat (Triticum aestivum L.). Indian $J$. Biochem. Biophys., 49: 257- 265.

Dutta, P. and Bera, A. K. 2007. Germination and seedling development of two contrasting mungbean cultivars under simulated moisture stress conditions. $J$. Food Legumes, 20: 169 - 172. 
FAO. 2011. The state of the world's land and water resources for food and agriculture (SOLAW) - Managing systems at risk. Food and Agriculture Organization of the United Nations, Rome and Earthscan, London.

Giannopolitis, C.N. and Ries, S.K. 1977. Superoxide dismutase. I. Occurrence in higher plants. Plant Physiol., 59: 309314.

Goth, L. 1991. A simple method for determination of serum catalase activity and revision of reference range. Clinica Chimica Acta, 196: 143- 151.

Jaleel, C. A., Manivannan, P., Lakshmanan, G. M. A., Gomathinayagam, M. and Paneerselvam, R. 2008c. Alterations in morphological parameters and photosynthetic pigment responses of Catharanthus roseus under soil water deficits. Colloids Surf. B: Biointerfaces, 62: $312-318$.

Jaleel, C. A., Manivannan, P., Wahid, A., Farooq, M., Al-Juburi, H. J., Somasundaram, R. and Paneerselvam, R. 2009. Drought stress in plants: A review on morphological characteristics and pigments composition. Int. J. Agric. Biol., 11: 100 - 105.

Jaworski, E.G. 1971. Nitrate reductase assay in intact plant tissues. Biochem. Biophys. Res. Commun., 43: 12741279.

Kumar, P. and Singh, R. A. 1991. Germination and metabolism in susceptible and tolerant mungbean genotypes under moisture stress. Indian J. Plant Physiology, 34: 267 - 270.

Michel, B. E. and Kaufmann, M. R. 1973. The osmotic potential of polyethylene glycol 6000. plant Physiol. 51 : 914 916.

Mohamed, M.H. and El Kramany, M.F. 2005. Salinity Tolerance of Some Mungbean Varieties. J. App. Sci. Res., 1: 78-84.
Moussa, H.R. and Abdel-Aziz, S.M. 2008. Comparative response of drought tolerant and drought sensitive maize genotypes to water stress. Aust. J. Crop Science, 1: 31- 36.

Naidu, T. C. M., Raju, N. and Narayanan, A. 2001. Screening of drought tolerance in greengram (Vigna radiata L. Wilezek) genotypes under receding soil moisture. Indian J. Plant Physiol., 6: 197 - 201.

Nair, J.S. and Ramaswamy, N.K. 2006. Differential response of antioxidant enzymes in wheat (Triticum aestivum L.) under PEG- induced water stress. Physiol. Mol. Biol. Plants, 12: 95 - 99.

Ranawake A. L., Dahanayaka N., Amarasingha U. G. S., Rodrigo W. D. R. J. and Rodrigo U. T. D. 2011. Effect of Water Stress on Growth and Yield of Mung Bean (Vigna radiata L). Tropical Agricultural Research \& Extension, 14(4).

Sairam, R.K. and Srivastava, G.C. 2001. Water stress tolerance of wheat (Triticum aestivum L.). Variations in hydrogen peroxide accumulation and antioxidant activity in tolerant and susceptible genotypes. J. Agron. Crop Sci., 186: 63- 70.

Sairam, R.K., Deshmukh, P.S. and Shukla, D.S. 1997. Tolerance of drought and temperature stress in relation to increased antioxidant enzyme activity in wheat. J. Agron. Crop Sci., 178: 171177.

Samra, J.S. 2004. Review and analysis of drought monitoring, declaration and management in India. Working Paper 84. International Water Management Institute, Colomobo, Sri Lanka. pp. 131.

Satbhai, R. D., Naik, R. M., Kale, A. A. and Desai, B. B. 1997. Effects of water stress on metabolic alterations in rabi sorghum. J. Maharashtra Agricultural Universities, 22: $158-160$. 
Siegel, B.Z. and Galston, A.W. 1967. The isoperoxidases of Pisum sativum. Physiol. Plant., 42: 212- 226.

Simova-Stoilova, L., Vaseva, I., Grigorova, B., Demirevska, K. and Feller, U. 2010. Proteolytic activity and cysteine protease expression in wheat leaves under severe soil drought and recovery. Plant Physiol. Biochem., 48: 200- 206.

Smirnoff, N. 1993. The role of active oxygen in response of plants to water deficit and desiccantion. New Phytol., $125: 27$ - 58.

Uddin S., Parvin S. and Awal M. A. 2013. Morpho-Physiological Aspects of Mungbean (Vigna radiata L.) in Response to Water Stress. International
Journal of Agricultural Science and Research (IJASR), Vol. 3, 137-148.

Zhang, M. S., Tan, F., Xie, B., Zhang, Q. T., Fu, Y. F., Yang, C. X. and Yang, Y. H. 2003. Relationship of peroxidation of membrane-lipid and membrane protection system in sweet potato under water stress with drought resistance. Scientia Agricultura Sinica, 36: 1395 1398.

Zlatev, Z. S., Lidon, F. C., Ramalho, J. C. and Yordanov, I. T. 2006. Comparison of resistance to drought of three bean cultivars. Biologia Plantarum, 50: 389 394.

\section{How to cite this article:}

Sibu Mandi, Anjan Kumar Pal, Rajib Nath and Suryakant Hembram. 2018. ROS Scavenging and Nitrate Reductase Enzyme Activity in Mungbean [Vigna radiata (L.) Wilczek] under Drought Stress. Int.J.Curr.Microbiol.App.Sci. 7(04): 1031-1039.

doi: https://doi.org/10.20546/ijcmas.2018.704.113 